CLINICAL STUDY

\title{
GH secretory pattern in young adults who discontinued GH treatment for GH deficiency and decreased longitudinal growth in childhood
}

Johan Svensson, Gudmundur Johannsson, Ali Iranmanesh ${ }^{1}$, Kerstin Albertsson-Wikland ${ }^{2}$, Johannes D Veldhuis ${ }^{3}$ and Bengt-Åke Bengtsson

Research Centre for Endocrinology and Metabolism, Sahlgrenska University Hospital, Göteborg, Sweden, ${ }^{1}$ Endocrine Section, Medical Service, Salem Veterans Affairs Medical Center, Salem, Virginia, USA, ${ }^{2}$ Pediatric Growth Research Center, Department of Pediatrics, Institute of the Health of Women and Children, Queen Silvia Children's Hospital, Sahlgrenska Academy of Göteborg University, Göteborg, Sweden and ${ }^{3}$ Endocrine Research Unit, Mayo Clinic, Rochester, Minnesota, USA

(Correspondence should be addressed to J Svensson; Email: Johan.Svensson@medic.gu.se)

\begin{abstract}
Objective: Some adolescents who discontinue GH treatment due to GH deficiency (GHD) and short stature in childhood do not have classical GHD at retesting in adult life. It is unknown whether there is a neuroendocrine disturbance in the spontaneous pattern of GH release in these patients.

Design/patients/methods: Thirty-seven adolescents, who had received treatment with GH due to impaired longitudinal growth, were included. The adolescents were divided into two groups; one (GHD; $n=19$ ) with classical GHD in adult life and another (GH sufficient (GHS); $n=18$ ) without classical adult GHD. One year after GH discontinuation, 24-h GH profiles were performed with blood sampling every $30 \mathrm{~min}$. Sixteen matched healthy controls were also studied. All blood samples were analysed using an ultrasensitive GH assay and then, approximate entropy (ApEn) and deconvolution analysis were performed.

Results: The GHD group had higher mean ApEn level than the healthy controls $(P<0.05)$. As measured by deconvolution analysis, they had lower basal GH secretion $(P<0.01)$, increased number of GH peaks $(P<0.001)$, but lower burst mass $(P<0.001)$, lower percentage pulsatile $\mathrm{GH}$ secretion $(P<0.001)$ and lower total GH secretion $(P<0.001)$, compared with control subjects. Adolescents in the GHS group had a pattern of 24-h GH release similar to that in healthy controls.

Conclusion: Young adults with childhood-onset severe GHD have a high-frequency, low-amplitude GH secretion with decreased orderliness. The adolescents without classical GHD in adult life maintain a pattern of spontaneous GH release that is not statistically different from that in the healthy controls.
\end{abstract}

European Journal of Endocrinology 155 91-99

\section{Introduction}

Hypopituitary adults with severe growth hormone $(\mathrm{GH})$ deficiency (GHD) have increased abdominal/visceral obesity, decreased lean and bone mass, and metabolic abnormalities including insulin resistance and disturbed lipoprotein pattern (1-3). Premature atherosclerosis (4) and increased mortality from cardiovascular disease have also been observed (5-8). These clinical characteristics are observed in adults with both childhood- and adult-onset disease $(9,10)$. Serum insulin-like growth factor-I (IGF-I) level, and bone and muscle mass, may, however, be more reduced in childhood-onset disease, whereas the impairment of serum lipid levels may be more marked in patients with adult-onset disease $(10,11)$.

The multiple abnormalities observed in GHD adults could suggest that adolescents receiving GH therapy for decreased longitudinal growth and inadequate $\mathrm{GH}$ secretion in childhood may need to continue the GH therapy also in adult life. Studies, in which young adults with GH therapy in childhood/adolescence have been retested, have shown that some, but not all, of these patients have persisting severe GHD according to the diagnostic criteria set in adult life $(12,13)$. Discontinuing GH therapy at final height in adolescents with severe GHD into adult life produces similar clinical characteristics as those observed in other groups of adult patients with GHD (14-22). Quality of life may, however, be less affected by GH discontinuation in this patient group (20). In addition, peak muscle and bone mass may never be obtained if the $\mathrm{GH}$ therapy is terminated too early as maximum muscle strength and bone density continuously improves several years after longitudinal growth has been completed $(10,23)$. Continued or reinstituted GH replacement can, however, maintain or reverse most of the abnormalities in 
body composition and in bone and lipid metabolism in this group of patients $(10,22,24)$.

Subjects with inadequate GH secretion and decreased longitudinal growth in childhood, but with normal GH reserve at retesting in adult life, have what appears to be a normal development in terms of body composition and metabolism during the first years after $\mathrm{GH}$ discontinuation (14-20). However, the transition studies with GH discontinuation have so far only had a duration of a few years (14-20), and the extent to which these patients may suffer from partial GHD later in life has, therefore, not been determined. The results of several studies suggest that also partial GHD can result in disturbed body composition and serum lipid pattern in hypopituitary adults $(25,26)$. Little is known whether the 24-h spontaneous GH secretory pattern differs between young adults with inadequate $\mathrm{GH}$ secretion and decreased longitudinal growth in childhood, but with normal GH reserve at retesting in adult life, and healthy young adult subjects.

In the present study, the young adults, previously treated in childhood/adolescence for decreased longitudinal growth and inadequate $\mathrm{GH}$ secretion, were included. The aim was to determine the spontaneous pattern of 24-h GH release in patients with persisting GHD (GHD group), or with a normal GH response at retesting in adult life (GH sufficient (GHS) group), vs healthy age- and body mass index (BMI)matched controls. One year after GH discontinuation, 24-h plasma GH profiles (sampling every $30 \mathrm{~min}$ ) were monitored in the GHD and GHS groups. Similar 24-h $\mathrm{GH}$ profiles were also performed in the healthy controls. Plasma GH concentrations were analysed using a highly sensitive chemiluminescence assay and GH secretory patterns were determined using deconvolution and approximate entropy (ApEn) analysis.

\section{Subjects and methods}

\section{Patients and controls}

Forty adolescent patients receiving GH treatment within clinical trials and 16 healthy control subjects were recruited for the study. Twenty-four-hour GH profiles were performed in 37 of the 40 patients and in all controls. Since the GH profiles were performed 1 year after $\mathrm{GH}$ discontinuation, three of the patients had withdrawn from the study during the first year. (One man with idiopathic, isolated GHD during childhood was not interested in further investigations after the baseline visit and two women with severe GHD withdrew from the study after 3 and 6 months, respectively, as a result of severe psychological symptoms, which were resolved after the reinstitution of GH replacement therapy). The present study, therefore, included 37 patients and 16 controls. The GH-treated subjects had been submitted for participation from 14 paediatric clinics. The criteria for inclusion were GHD, idiopathic or organic, and isolated or multiple anterior pituitary hormone deficiencies. The patients had received GH treatment for the past three consecutive years and were otherwise being considered to end GH treatment. Patients who were not considered for inclusion were those who planned to finalise treatment for reasons other than reaching final height, those older than 25 years at the time of inclusion, pharmacological treatment for psychiatric disease, or mental retardation. The patients were partly selected for the study so as to have approximately half the patients with childhoodonset, idiopathic, isolated GHD and half with organic hypothalamic/pituitary disease with or without multiple pituitary hormone deficiencies.

Severe GHD in adult life was defined as: i) another anterior pituitary hormone deficiency associated with a spontaneous GH peak of less than $3 \mu \mathrm{g} / \mathrm{l}$ (14 subjects), or ii) an organic hypothalamic/pituitary disease associated with a $\mathrm{GH}$ peak of less than $3 \mu \mathrm{g} / \mathrm{l}$ during an insulin tolerance test (four subjects), or iii) in the absence of an organic hypothalamic/pituitary disease, a $\mathrm{GH}$ peak of less than $3 \mu \mathrm{g} / \mathrm{l}$ during two $\mathrm{GH}$ stimulation tests (one patient). Thus, using these criteria, 19 of the 37 patients were classified as having severe GHD in adult life, whereas 18 patients were classified as GHS.

Most patients in the GHS group had idiopathic and isolated pituitary deficiency, whereas most patients in the GHD group had organic hypothalamic/pituitary disease (Table 1). All patients with brain neoplasia and acute lymphoblastic leukaemia had received irradiation in the hypothalamic/pituitary area. Patients with other anterior pituitary hormone deficiencies received, when required, stable replacement therapy with glucocorticoids (cortisone acetate; mean, $20 \mathrm{mg}$; range, $15-30 \mathrm{mg} /$ day), thyroid hormone (levothyroxine; mean, $0.1 \mathrm{mg}$; range, $0.05-0.15 \mathrm{mg} /$ day) and gonadal steroids. The period of $\mathrm{GH}$ treatment was,

Table 1 Causes of the pituitary deficiency, degree of pituitary deficiency after reevaluation, and $\mathrm{GH}$ treatment years and onset of puberty in $19 \mathrm{GH}$ deficient (GHD) and $18 \mathrm{GH}$ sufficient (GHS) patients. All values are shown as number except for age at $\mathrm{GH}$ start and $\mathrm{GH}$ treatment years, which are given as means (S.E.M.)

\begin{tabular}{lrc}
\hline & GHS & GHD \\
\hline Causes of the pituitary deficiency & 17 & 9 \\
$\quad$ Idiopathic & 1 & 2 \\
$\quad$ Acute lymphoblastic leukaemia & & 5 \\
$\quad$ Brain tumour & & 3 \\
$\quad$ Other & 17 & \\
Degree of pituitary deficiency after & 1 & 4 \\
reevaluation & & 5 \\
$\quad$ Isolated GHD & $11.7(0.9)$ & $10.5(0.7)$ \\
$\quad$ One additional deficiency & $5.6(0.7)$ & $9.2(0.7)^{\mathrm{a}}$ \\
$\quad$ Two additional deficiencies & & \\
$\quad$ Three additional deficiencies & & \\
Age at GH start (years) & & \\
GH treatment years (years) & & \\
\hline
\end{tabular}

${ }^{\text {a }} P<0.001$ vs GHS group. 
however, shorter in the GHS group (Table 1). Furthermore, a prospective evaluation showed that age at onset of puberty was somewhat higher in the GHS group than in the GHD group ( 14 vs 13 years, respectively).

Sixteen healthy control subjects were recruited. They were selected from subjects who responded to an advertisement and were closely matched with the GHS group in terms of age, gender, body height, body weight and BMI (Table 2).

\section{Study protocol}

During a stabilising period of 3 months, all patients received a standardised dose of $\mathrm{GH}, 0.03 \mathrm{mg} / \mathrm{kg}$ per day $(0.1 \mathrm{IU} / \mathrm{kg}$ per day). After a baseline visit, the $\mathrm{GH}$ treatment was discontinued. One year after this, a GH profile was performed. During the year between the GH discontinuation and when the 24-h GH profile was performed, the patients were seen at the home paediatric clinic. The results of other measurements than the 24-h $\mathrm{GH}$ profiles have been published elsewhere (17-20).

\section{Body composition}

Body weight was measured in the morning to the nearest $0.1 \mathrm{~kg}$ with the subject wearing indoor clothing, and body height was measured barefoot to the nearest $0.01 \mathrm{~m}$. The BMI was calculated as body weight in kilograms divided by height in metres squared. Dual energy x-ray absorptiometry (DEXA) was performed using a whole body scanner (Lunar DPX-L, Lunar Corp.; Madison, WI, USA). Total body fat (BF) and lean body mass (LBM) were analysed using the 1.31 software version. Precision errors for the scanner used (system number 7156), as determined from double examinations in 10 healthy subjects, were $1.7 \%$ for BF and $0.7 \%$ for LBM.

\section{Ethical considerations}

The study was approved by the Ethical Committee of the University of Göteborg and informed consent was obtained from each subject before the start of the study.

\section{GH profiles}

GH secretory status was assessed 1 year after GH discontinuation by 24-h GH measurements (beginning $1000 \mathrm{~h}$ ) from repeated 30-min blood sampling using a withdrawal pump. Plasma GH concentrations and GH secretory patterns were analysed (blinded) by deconvolution analysis and analysis of ApEn.

The patients and the controls were allowed to maintain their ordinary consumption of caffeine and/or tobacco during the profiles. Ingestion of alcohol was not allowed the day before the profiles or during the profiles. The patients were allowed to move freely within the ward. Standardised meals were given at 0800 , 1200,1600 and $1900 \mathrm{~h}$. The patients were instructed to go to bed at the same time as they used to do at home.

\section{Deconvolution analysis}

Two-compartment deconvolution analysis was applied. Fixed GH half-life was used (3.5 min fast component, 20.9 min slow component; fractional amplitude of slow component, 0.63) as previously determined directly in growth hormone-releasing hormone (GHRH)-stimulated and then somatostatin-suppressed adults (27). Daily pulsatile $\mathrm{GH}$ secretion is the product of secretory-burst frequency and the (mean) mass of GH released per pulse. Basal secretion represents the time-invariant interpulse component of the GH release profile (28). Analysis was carried out requiring 95\% joint statistical confidence intervals for all GH secretory-burst amplitudes (29, 30). The analyst was blinded to the time series assignments.

\section{Approximate entropy}

ApEn quantifies the serial orderliness or pattern regularity of the (hormone) release process over $24 \mathrm{~h}$ (31). ApEn parameters of $m=1$ (series length) and $r=35 \%$ (threshold) of the intraseries s.D. were used, as described previously (32). ApEn was normalised by calculating the ratio of observed to 1000 randomly shuffled versions of each GH time series. Thus, ApEn

Table 2 Characteristics in the study population of in $19 \mathrm{GH}$ deficient (GHD) patients, $18 \mathrm{GH}$ sufficient (GHS) patients, and 16 healthy controls. Lean body mass and body fat was estimated using DEXA. All values are shown as the mean (S.E.M.). The controls and the GHS group were comparable in all variables given in this table.

\begin{tabular}{|c|c|c|c|c|}
\hline & Controls & GHS & GHD & $P$-value* \\
\hline Age (years) & $19.3(0.4)$ & $19.8(0.3)$ & $19.7(0.4)$ & 0.96 \\
\hline Sex (men/women) & $12 / 4$ & $14 / 4$ & $17 / 2$ & \\
\hline Body height $(\mathrm{cm})$ & $173(2)$ & $171(2)$ & $174(2)$ & 0.48 \\
\hline Body weight $(\mathrm{kg})$ & $67.3(3.5)$ & 65.5 (3.2) & $71.0(3.1)$ & 0.43 \\
\hline BMI $\left(\mathrm{kg} / \mathrm{m}^{2}\right)$ & $22.3(0.8)$ & $22.3(0.8)$ & $23.4(0.8)$ & 0.35 \\
\hline Lean body mass $(\mathrm{kg})$ & $51.1(2.2)$ & $49.1(1.9)$ & $46.4(1.6)$ & 0.13 \\
\hline Body fat $(\mathrm{kg})$ & $12.5(2.6)$ & $13.3(2.2)$ & $21.3(2.1)^{\mathrm{a}, \mathrm{c}}$ & $<0.05$ \\
\hline Serum IGF-I $(\mu \mathrm{g} / \mathrm{L})$ & $374(26)$ & $409(29)$ & $190(31)^{b, d}$ & $<0.001$ \\
\hline
\end{tabular}

${ }^{\mathrm{a}} P<0.01$ vs controls; ${ }^{\mathrm{b}} P<0.001$ vs controls; ${ }^{\mathrm{c}} P<0.01$ vs GHS group; ${ }^{\mathrm{d}} P<0.001$ vs GHS group. ${ }^{*} P$-values (between all three groups) are based on the Kruskal-Wallis ANOVA test by ranks. $P$-Values (between two groups) are based on a post hoc analysis using the Mann-Whitney $U$-test. 
ratios approaching 1.0 denote mean expected random behaviour. Lower ApEn ratios (at equal series lengths and parameter values as used here) denote greater orderliness (regularity) of moment-to-moment hormone release. Conversely, high ratios are observed for $\mathrm{GH}$ in acromegaly (33) and in women compared to men (32).

\section{Biochemical assays}

Plasma GH concentrations were measured using an ultrasensitive chemiluminescence assay with a lower limit of detectability of $0.002 \mu \mathrm{g} / \mathrm{l}$ (at two standard deviations (s.D.) above assay blank) and $0.005 \mu \mathrm{g} / \mathrm{l}$ (at 3 s.D. above assay blank), as previously described (29). The median intra- and inter-assay coefficients of variation $(\mathrm{CV})$ were 6.3 and $7.4 \%$. All samples from an individual were assayed together.

The serum concentration of IGF-I was determined after hydrochloric acid - ethanol precipitation of binding proteins using RIA (Nichols Institute Diagnostics; San Juan Capistrano, CA, USA) with within-assay CV values of 2.5 and $4.2 \%$ at serum concentrations of 125 and $345 \mu \mathrm{g} / \mathrm{l}$, respectively.

\section{Statistical analysis}

Descriptive statistical results are presented as the mean (s.E.M.). Differences among all the three study groups were accessed using the Kruskal-Wallis ANOVA test by ranks. In the variables, in which there was a significant difference between the three study groups, post hoc analyses were performed using the Mann-Whitney $U$-test. A one-way ANOVA was also performed, in which $\mathrm{BF}$, as measured using DEXA, was used as a covariant. Correlations were sought using the Spearman rankorder correlation test. A two-tailed $P$-value $\leq 0.05$ was considered significant.

\section{Results}

\section{Age, body composition and serum IGF-I}

The patients in the GHS group and the healthy controls were comparable in all variables given in Table 2. The GHD group was similar to the other two study groups in terms of age, gender distribution, body height, body weight, BMI and LBM as estimated using DEXA. BF, as estimated using DEXA, and serum IGF-I concentration were, however, higher and lower respectively in the GHD group as compared with the other two groups.

\section{Nadir and peak GH concentrations}

The mean nadir (minimum) GH concentration during the 24-h GH profiles was statistically similar in all the three study groups (control group $0.10(0.03) \mu \mathrm{g} / \mathrm{l}$, GHS group $0.06(0.01) \mu \mathrm{g} / \mathrm{l}$, GHD group $0.06(0.01) \mu \mathrm{g} / \mathrm{l})$.
The mean peak GH concentration during the 24-h GH profiles was lower in the GHD group $(1.4(0.3) \mu \mathrm{g} / \mathrm{l})$ than that in the GHS $(10.2(1.5) \mu \mathrm{g} / \mathrm{l}, P<0.001$ vs GHD group) and the control group (9.5 (0.9) $\mu \mathrm{g} / \mathrm{l}, P<0.001$ vs GHD group), but there was no statistical difference between the GHS and the control group.

\section{Deconvolution analysis}

The patients in the GHD group had lower basal GH secretion rate, increased half-duration of GH secretory bursts and number of GH peaks, but lower mean interburst interval and mean pulse area (burst mass) compared with the other two study groups. Basal, pulsatile and total GH secretion, and the percentage of total GH secretion that was pulsatile, were decreased in the GHD group as compared with both the GHS and the control group. In contrast, the young adults in the GHS group had a pattern of 24-h GH release that was statistically similar to that in the healthy controls. Number of GH peaks, basal GH secretion and total GH secretion are shown in Fig. 1A-C, whereas other results of the deconvolution analysis are shown in Table 3.

\section{ApEn analysis}

The patients in the GHD group had a higher mean ApEn ratio than both the patients in the GHS group and the healthy controls (Fig. 1D). In the GHS group, mean ApEn ratio was similar as in the healthy controls (Fig. 1D).

\section{Correlations}

In the total study population (patients and controls; $n=53$ ), serum IGF-I concentration correlated positively with peak GH concentration $(r=0.65, P<0.001)$, percentage pulsatile GH secretion $(r=0.58 ; P<0.001)$, mean pulse area $(r=0.52 ; P<0.001)$, pulsatile $\mathrm{GH}$ secretion $(r=0.49 ; P<0.001)$, total GH secretion $(r=0.46 ; P<0.001)$ and mean interburst interval $(r=0.44 ; P<0.01)$ and negatively with half-duration of GH bursts $(r=-0.54 ; P<0.001)$ and number of $\mathrm{GH}$ peaks $(r=-0.49 ; P<001)$. In the total study population, serum IGF-I concentration was not correlated with nadir GH concentration or with basal GH secretion (data not shown). In the patient group (combined GHS and GHD groups; $n=37$ ), serum IGF-I concentration correlated with all measures of 24-h GH secretion except for nadir $\mathrm{GH}$ concentration $(r=0.20)$.

Serum IGF-I concentration was not correlated with ApEn ratio in the total study population $(n=53)$, in the patient group $(n=37)$, or in the GHD group $(n=19)$ (data not shown).

In the total study population $(n=53), \mathrm{BF}$, as measured using DEXA, correlated positively with half-duration of GH secretory bursts $(r=0.49, P<0.001)$, ApEn ratio 
A

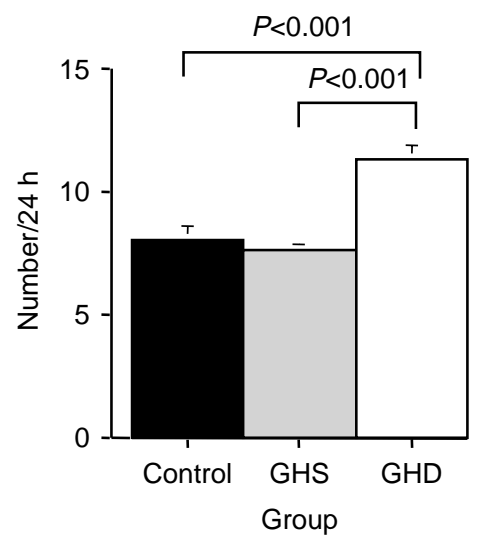

C

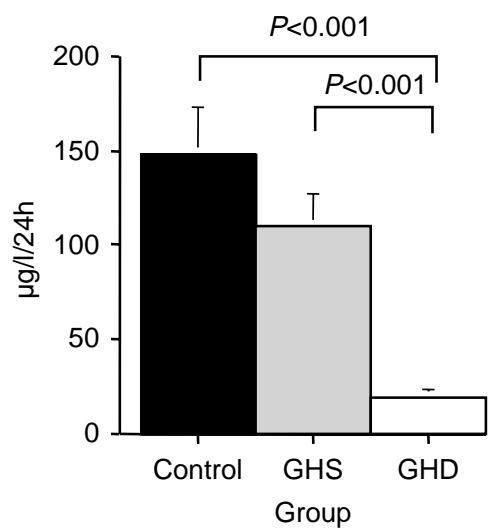

B

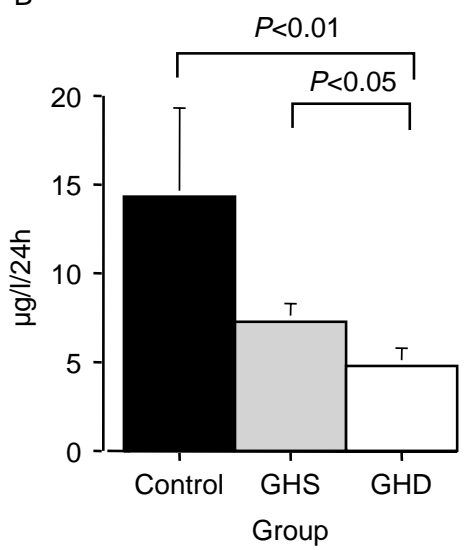

D

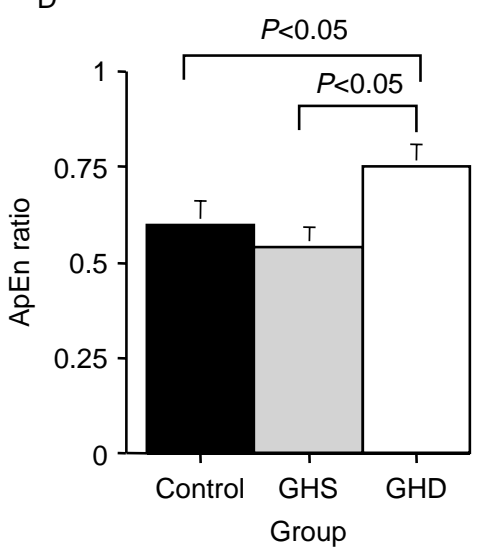

Figure 1 (A) Number of GH peaks, (B) basal GH secretion, (C) total GH secretion and (D) approximate entropy (ApEn) ratios obtained from 24-h plasma GH profiles in $19 \mathrm{GH}$ deficient (GHD) patients, $18 \mathrm{GH}$ sufficient (GHS) patients, and 16 healthy controls. All values are shown as the mean (S.E.M.). An ApEn ratio approaching 1.0 denotes approximately random GH profiles (indistinguishable from 1000 randomly shuffled versions of the same data series).

$(r=0.36, P<0.01)$ and number of $\mathrm{GH}$ peaks $(r=0.30$, $P<0.05)$ and negatively with mean peak GH concentration $(r=-0.61, P<0.001)$, pulse area $(r=-0.58$, $P<0.001)$, total GH secretion $(r=-0.55, P<0.001)$, pulsatile GH secretion $(r=-0.54, P<0.001)$, percentage pulsatile $\mathrm{GH}$ secretion $(r=-0.46, P<0.001)$ and basal GH secretion $(r=-0.42, P<0.01)$.
In the patient group (combined GHS and GHD groups; $n=37$ ), BF, as measured using DEXA, was significantly correlated with GH secretion (data not shown). In the GHD group $(n=19)$, BF correlated negatively with halfduration of GH secretory bursts $(r=-0.67, P<0.001)$, and tended to correlate positively with mean interburst interval $(r=0.44, P=0.07)$. There was no correlation

Table 3 Deconvolution analysis of 24-h plasma GH concentration profiles in 19 GH deficient (GHD) patients, 18 GH sufficient (GHS) patients, and 16 healthy controls. All values are shown as the mean (S.E.M.).

\begin{tabular}{lccrc}
\hline & Controls & GHS & GHD & $\boldsymbol{P}^{\text {-value }}$ \\
\hline Basal GH secretion rate $(\mu \mathrm{g} / \mathrm{l}$ per min) & $0.010(0.003)$ & $0.005(0.001)$ & $0.003(0.001)^{\mathrm{a}, \mathrm{c}}$ & $<0.01$ \\
Half-duration of GH secretory bursts $(\min )$ & $17.5(1.0)$ & $18.1(1.0)$ & $24.9(0.6)^{\mathrm{b}, \mathrm{d}}$ & $<0.001$ \\
Mean interburst interval (min) & $184(12)$ & $193(11)$ & $131(8)^{\mathrm{a}, \mathrm{d}}$ & $<0.001$ \\
Pulse area (pulse mass; $\mu \mathrm{g} / \mathrm{l}$ per min) & $17.4(3.0)$ & $13.5(2.1)$ & $1.48(0.39)^{\mathrm{b}, \mathrm{d}}$ & $<0.001$ \\
Pulsatile GH secretion $(\mu \mathrm{g} / \mathrm{l}$ per 24 h) & $134.2(21.3)$ & $102.7(16.8)$ & $14.4(3.4)^{\mathrm{b}, \mathrm{d}}$ & $<0.001$ \\
Percentage pulsatile GH secretion & $78(3)$ & $92(1)$ & $67(5)^{\mathrm{b}, \mathrm{d}}$ & $<0.001$ \\
\hline
\end{tabular}

${ }^{\mathrm{a}} P<0.01 ;{ }^{\mathrm{b}} P<0.001$ vs controls; ${ }^{\mathrm{c}} P<0.05$; ${ }^{\mathrm{d}} P<0.001$ vs GHS group. ${ }^{*} P$-values (between all three groups) are based on the Kruskal-Wallis ANOVA test by ranks. $P$-Values (between two groups) are based on a post hoc analysis using the Mann-Whitney $U$-test. 
between $\mathrm{BF}$ and other measures of $\mathrm{GH}$ secretory patterns (all $P$-values $>0.13$ ) in the GHD group.

\section{Analysis of covariance}

To evaluate the role of the increased BF in the GHD group, ANOVA was performed. These analyses, in which $\mathrm{BF}$ was used as a covariant, showed that all the observed between-group differences in measures of GH secretory patterns remained significant except for the difference in ApEn ratio between the GHD and the control group $(P=0.07)$ (data not shown).

\section{Discussion}

This study distinguishes patterns of daily GH release in young adults after discontinuation of GH-treatment used for inadequate GH secretion and decreased longitudinal growth in childhood. The results of the 24-h GH profiles show that the patients with continued GHD in adult life had a high-frequency, low-amplitude 24-h pattern of GH release. The patients who were considered GHS in adult life maintained a 24-h pattern of spontaneous $\mathrm{GH}$ release similar to that in healthy controls.

In this study, blood sampling was performed every 30 min over $24 \mathrm{~h}$. Previous validation of the deconvolution analysis have shown valid daily GH secretion rate estimates based on 30-min sampling, although the sensitivity for absolute peak number is lower than that using 10-20 min sampling schedules (34). Using a similar methodology, we previously identified clear differences in the 24-h GH secretory pattern in GHD adults with low and normal serum IGF-I concentrations compared with healthy subjects (35). In that analysis (35) and the present study comparing the GHD patients and the healthy controls, there was a between-group difference in mean number of peaks. It is therefore unlikely that any major between-group differences were not detected using the 30-min sampling. Analysis of normalised ApEn is less dependent on the sampling frequency, as indicated in a previous study using 60-min sampling protocol that yielded strong contrasts between patients with acromegaly and normal individuals in the regularity of GH secretory patterns $(31,36)$.

Fixed GH half-life was used in this study based on previous determinations in GHRH-stimulated and then somatostatin-suppressed adults (27). This is possible, as GH kinetics is very constant (37). Marked GH-receptor blockade via pegvisomant in adults does not alter in vivo GH kinetics after bolus infusion, an intervention that creates tissue hyposomatotropism (38). Systemic hyposomatotropism of critical illness or sarcopenia of aging, and IGF-I depletion in fasting, also do not alter GH kinetics (39-46). Lifetime developmental strata, whether in the neonatal, pubertal, adult or in the senescent individual (47-52) and excessive GH secretion in acromegaly $(53,54)$, do not influence the GH half-life. End-stage hepatic and renal disease as well as i.v. bolus injections of GH to healthy men prolong the GH half-life $(55,56)$. Thus, GH kinetics is very stable, except in the state of severe organ failure and during pharmacological administration of recombinant GH.

The patients in the GHS group were comparable by way of age, gender distribution, body height, body weight, BMI, LBM and BF to healthy controls. These factors did, therefore probably, not influence the comparisons between these two groups. The correlation analyses showed that the measures of GH secretory patterns were highly related to BF in the total study population $(n=53)$ as well as in the patient group $(n=37)$, whereas in the GHD group $(n=19)$, the only significant correlation was the negative one between half-duration of GH secretory bursts and BF. Therefore, although the number of patients was relatively small in the latter analysis, it appears that the relation between 24-h spontaneous GH release and BF was weak in the GHD group. To clarify if the observed differences in spontaneous 24-h GH release were dependent on the increased BF in the GHD group, we repeated the statistical analyses using ANOVA. In these analyses, using $\mathrm{BF}$ as a covariant, all the between-group differences in measures of GH secretory patterns remained significant except for the difference in ApEn ratio between the GHD and the control group $(P=0.07)$ (data not shown). It is, therefore, unlikely that the observed alterations in 24-h spontaneous GH release among the study groups were due to the increased BF in the GHD group.

One hypothesis motivating this study was that not only absolute GH levels, but also the pattern of the 24-h $\mathrm{GH}$ release, may be important for the effects of $\mathrm{GH}$ administration. In rodents, pulsatile (intermittent) $\mathrm{GH}$ delivery is more effective in increasing longitudinal growth than continuous GH delivery (57). However, GHS and controls exhibited no difference in multiple measures of spontaneous 24-h GH release. Therefore, the pattern of GH release observed in young adult life cannot explain why patients in the GHS group had decreased longitudinal growth in childhood. An alternative speculative explanation could be that in normal subjects there is a very large increase in GH secretion during puberty (29), and this increase could have been inadequate or delayed in the GHS group, whereas GH levels were sufficiently high in adult life. In possible support of this, the patients in the GHS group had a mean onset of puberty at a relatively high age (14 years).

The patients in the GHD group exhibited the greatest detectable GH pulse frequency, along with the lowest pulse area. The anomalous GH secretory pattern mimics that previously observed in other groups of GHD adults and confirms that a low-amplitude, pulsatile GH secretion persists in adult GHD patients $(35,58,59)$. Although pulsatile GH secretion persisted in patients with GHD, the relative amount of total GH secretion that 
was pulsatile was decreased. Therefore, GH secretion was more nearly continuous in the GHD group than in the other study groups. This pattern of GH release may, based on that previously observed in rodents, be less effective in stimulating longitudinal growth (57). However, the results of some short-term human studies suggest that a constant $\mathrm{GH}$ level of a certain magnitude may be more important than GH pulsatility (60). We cannot, therefore, exclude the possibility that in the GHD group, the decreased longitudinal growth in childhood was mainly caused by their low absolute levels of GH.

Mean ApEn ratio was higher in the GHD group than in the other two groups. This outcome quantitates relatively greater disorderliness of GH secretion, which has not been associated with decreased longitudinal growth (61). In fact, ApEn is high in puberty $(61)$, acromegaly $(31,36)$ and under exogenous GHRH and/or GHRP-2 drive $(62,63)$. The increase in ApEn ratio in the GHD group, therefore, suggests increased GHRH/GHRP drive and/or decreased IGF-I-dependent negative feedback. The former, if verified, could be hypothesised to be a compensatory phenomenon in order to restore $\mathrm{GH}$ action/secretion.

The present results give further evidence that a relatively high percentage of patients with short stature and inappropriate GH secretion in childhood do not have severe GHD into adult life $(12,13)$. In addition, this study shows that these young adult patients have a normal spontaneous pattern of 24-h GH release compared with healthy controls. We (17-19) and others (14-16) have also shown that these patients with normal GH secretion in adult life display normal longitudinal changes in body composition, muscle strength, bone metabolism and serum lipids during the first year after GH discontinuation (14-20). In the present study, there was, however, a weak non-significant tendency towards lower total GH secretion in the GHS patients than in the healthy controls. Furthermore, studies of GH discontinuation in young adults have extended for only a few years. Thus, whether GHS patients will maintain normal longitudinal body composition and metabolism throughout their entire lifespan remains unknown. Further studies are therefore needed to determine whether the metabolic syndrome in middle age, or frailty in late life, may be more frequent in the patients with idiopathic isolated $\mathrm{GH}$ deficiency in childhood.

In conclusion, this study distinguishes patterns of daily GH release in young adults after discontinuation of $\mathrm{GH}$ treatment initiated for inadequate $\mathrm{GH}$ secretion and decreased longitudinal growth in childhood. The results of the 24-h GH profiles show that patients considered to be GHD in adult life maintain a high-frequency, lowamplitude 24-h pattern of GH release. Patients considered to be GHS in adult life exhibit a normal pattern of 24-h GH release. Therefore, the pattern of GH secretion observed in young adult life cannot explain why GHS patients had inappropriate GH secretion and decreased longitudinal growth in childhood.

\section{Acknowledgements}

We are indebted to Lena Wirén, Ingrid Hansson, and Sigrid Lindstrand at the Research Centre for Endocrinology and Metabolism for their skilful technical support.

\section{References}

1 De Boer H, Blok G-J \& Van Der Veen E. Clinical aspects of growth hormone deficiency in adults. Endocrine Reviews 199516 63-86.

2 Carroll P, Christ E, Bengtsson B- $\AA$, Carlsson L, Christiansen J, Clemmons D, Hintz R, Ho K, Laron Z, Sizonenko P, Sönksen P, Tanaka $\mathrm{T} \&$ Thorner MO. Growth hormone deficiency in adulthood and the effects of growth hormone replacement: a review. Journal of Clinical Endocrinology and Metabolism $1998 \mathbf{8 3}$ 382-395.

3 Drake W, Howell S, Monson JP \& Shalet SM. Optimizing GH therapy in adults and children. Endocrine Reviews 200122 425-450.

4 Markussis V, Beshyah S, Fisher C, Sharp P, Nicolaides A \& Johnston D. Detection of premature atherosclerosis by high-resolution ultrasonography in symtom-free hypopituitary adults. Lancet $19923401188-1192$.

5 Rosén T \& Bengtsson B-A. Premature mortality due to cardiovascular diseases in hypopituitarism. Lancet 1990336 285-288.

6 Bülow B, Hagmar L, Mikoczy Z, Nordström C \& Erfurth E. Increased cerebrovascular mortality in patients with hypopituitarism. Clinical Endocrinology $1997 \mathbf{4 6}$ 75-81.

7 Tomlinson J, Holden N, Hills R, Wheatley K, Clayton R, Bates A, Sheppard M \& Stewart P. Association between premature mortality and hypopituitarism, West Midlands Prospective Hypopituitary Study Group. Lancet 2001357 425-431.

8 Svensson J, Bengtsson B-Å, Rosén T, Odén A \& Johannson G. Malignant disease and cardiovascular morbidity in hypopituitary adults with or without growth hormone replacement therapy. Journal of Clinical Endocrinology and Metabolism $2004 \mathbf{8 9}$ 3306-3312.

9 Capaldo B, Patti L, Oliviero U, Longobardi S, Pardo F, Vitale F, Fazio S, Di Rella F, Biondi B, Lombardi G \& Sacca L. Increased arterial intima-media thickness in childhood-onset growth hormone deficiency. Journal of Clinical Endocrinology and Metabolism 1997 82 1378-1381.

10 Koranyi J, Svensson J, Götherström G, Sunnerhagen K, Bengtsson B-Å \& Johannsson G. Baseline characteristics and the effects of five years of growth hormone $(\mathrm{GH})$ replacement therapy in adults with $\mathrm{GH}$ deficiency of childhood or adulthood onset; a comparative, prospective study. Journal of Clinical Endocrinology and Metabolism $2001864693-4699$.

11 Attanasio A, Lamberts S, Matranga A, Birkett M, Bates P, Valk N, Hilsted J, Bengtsson B-Å \& Strasburger C. Adult growth hormone (GH)-deficient patients demonstrate heterogeneity between childhood onset and adult onset before and during human $\mathrm{GH}$ treatment. Journal of Clinical Endocrinology and Metabolism 1997 82 82-88.

12 Cacciari E, Tassoni P, Parisi G, Pirazzoli P, Zucchini S, Mandini M, Cicognani A \& Balsamo A. Pitfalls in diagnosing impaired growth hormone $(\mathrm{GH})$ secretion: retesting after replacement therapy of 63 patients defined as GH deficient. Journal of Clinical Endocrinology and Metabolism 199274 1284-1289.

13 Shalet SM, Toogood A, Rahim A \& Brennan B. The diagnosis of growth hormone deficiency in children and adults. Endocrine Reviews 199819 203-223.

14 Rutherford O, Jones D, Round J, Buchanan C \& Preece M. Changes in skeletal muscle and body composition after discontinuation of growth hormone treatment in growth hormone deficient adults. Clinical Endocrinology 199134 469-475. 
15 Colle M \& Auzerie J. Discontinuation of growth hormone therapy in growth-hormone-deficient patients: assessment of body fat mass using bioelectrical impedance. Hormone Research 199339 192-196.

16 Ogle G, Moore B, Lu P, Craighead A, Briody J \& Cowell C. Changes in body composition and bone density after discontinuation of growth hormone therapy in adolescence: an interim report. Acta Paediatrica 1994399 (Suppl) 3-7.

17 Johannsson G, Albertsson-Wikland K \& Bengtsson B-Å. Discontinuation of growth hormone $(\mathrm{GH})$ treatment: metabolic effects in GH-deficient and GH-sufficient adolescent patients compared with control subjects. Journal of Clinical Endocrinology and Metabolism $1999 \mathbf{8 4} 4516-4524$.

18 Fors H, Bjarnason R, Wirén L, Albertsson-Wikland K, Bosaeus I, Bengtsson B-A \& Johannsson G. Currently used growth-promoting treatment of children results in normal bone mass and density, A prospective trial of discontinuing growth hormone treatment in adolescents. Clinical Endocrinology 200155 617-624.

19 Hulthen L, Bengtsson B-Å, Sunnerhagen K, Hallberg L, Grimby G \& Johannsson G. GH is needed for the maturation of muscle mass and strength in adolescents. Journal of Clinical Endocrinology and Metabolism $2001 \mathbf{8 6}$ 4765-4770.

20 Wirén L, Johannsson G \& Bengtsson B-Å. A prospective investigation of quality of life and psychological well-being after the discontinuation of $\mathrm{GH}$ treatment in adolescent patients who had GH deficiency during childhood. Journal of Clinical Endocrinology and Metabolism 200186 3494-3498.

21 Drake W, Carroll P, Maher K, Metcalfe K, Camacho-Hübner C, Shaw N, Dunger D, Cheetham T, Savage M \& Monson JP. The effect of cessation of growth hormone $(\mathrm{GH})$ therapy on bone mineral accretion in GH-deficient adolescents at the completion of linear growth. Journal of Clinical Endocrinology and Metabolism $2003 \mathbf{8 8}$ 1658-1663.

22 Carroll P, Drake W, Maher K, Metcalfe K, Shaw N, Dunger D, Cheetham T, Camacho-Hübner C, Savage M \& Monson JP. Comparison of continuation or cessation of growth hormone (GH) therapy on body composition and metabolic status in adolescents with severe GH deficiency at completion of linear growth. Journal of Clinical Endocrinology and Metabolism 200489 3890-3895.

23 Kaufman J, Taelman P, Vermeulen A \& Vandeweghe M. Bone mineral status in growth hormone-deficient males with isolated and multiple pituitary deficiences of childhood onset. Journal of Clinical Endocrinology and Metabolism 199274 118-123.

24 Vahl N, Juul A, Jorgensen J, Orskov H, Skakkeback N \& Christiansen JS. Continuation of growth hormone $(\mathrm{GH})$ replacement in GH-deficient patients during transition from childhood to adulthood: a two-year placebo-controlled study. Journal of Clinical Endocrinology and Metabolism 200085 1874-1881.

25 Colao A, Cerbone G, Pivonelli R, Aimaretti G, Loche S, Di Somma C, Faggiano A, Corneli G, Ghigo E \& Lombardi G. The growth hormone (GH) response to the arginine plus GH-releasing hormone test is correlated to the severity of lipid profile abnormalities in adult patients with GH deficiency. Journal of Clinical Endocrinology and Metabolism $1999841277-1282$.

26 Murray R, Adams J \& Shalet SM. Adults with partial growth hormone deficiency have an adverse body composition. Journal of Clinical Endocrinology and Metabolism 200489 1586-1591.

27 Faria A, Veldhuis JD, Thorner MO \& Vance M. Half-life of endogenous growth hormone $(\mathrm{GH})$ disappearance in normal man after stimulation of GH secretion by GH-releasing hormone and suppression with somatostatin. Journal of Clinical Endocrinology and Metabolism 198968 535-541.

28 Veldhuis JD \& Johnson M. Specific methodological approaches to selected contemporary issues in deconvolution analysis of pulsatile neuroendocrine data. Methods Neuroscience 199528 25-92.

29 Veldhuis JD, Liem A, South S, Weltman A, Weltman J, Clemmons D, Abbott R, Mulligan T, Johnson M, Pincus S, Straume M \& Iranmanesh A. Differential impact of age, sex steroid hormones, and obesity on basal versus pulsatile growth hormone secretion in men as assessed in an ultrasensitive chemiluminescence assay. Journal of Clinical Endocrinology and Metabolism $1995 \mathbf{8 0}$ 3209-3222.

30 Van den Berg G, Veldhuis JD, Frohlich M \& Roelfsema F. An amplitude-specific divergence in the pulsatile mode of growth hormone $(\mathrm{GH})$ secretion underlies the gender difference in mean GH concentrations in men and premenopausal women. Journal of Clinical Endocrinology and Metabolism $1996 \mathbf{8 1}$ 2460-2467.

31 Veldhuis JD \& Pincus S. Orderliness of hormone release patterns: a complementary measure to conventional pulsatile and circadian analyses. Journal of Clinical Endocrinology and Metabolism 1998 138 358-362.

32 Pincus S, Gevers E, Robinson I, van den Berg G, Roelfsema F, Hartman M \& Veldhuis JD. Females secrete growth hormone with more process irregularity than males in both humans and rats. American Journal of Physiology 1996270 E107-E115.

33 Hartman M, Pincus S, Johnson M, Matthews D, Faunt L, Vance M, Thorner MO \& Veldhuis JD. Enhanced basal and disorderly growth hormone secretion distinguish acromegalic from normal pulsatile growth hormone release. Journal of Clinical Investigation 199494 1277-1288.

34 Hartman M, Faria A, Vance M, Johnson M, Thorner MO \& Veldhuis JD. Temporal structure of in vivo growth hormone secretory events in man. American Journal of Physiology 1991260 E101-E110.

35 Svensson J, Veldhuis J, Iranmanesh A, Bengtsson B- $\AA$ \& Johannsson G. Increased orderliness of growth hormone $(\mathrm{GH})$ secretion in GH deficient adults with low serum insulin-like growth factor-I. Journal of Clinical Endocrinology and Metabolism $2002872863-2869$.

36 Pincus S, Hartman M, Roelfsema F, Thorner MO \& Veldhuis JD. Hormone pulsatility discrimination via coarse and short time sampling. American Journal of Physiology 1999277 E948-E957.

37 Giustina A \& Veldhuis JD. Pathophysiology of the neuroregulation of growth hormone secretion in experimental animals and the human. Endocrine Reviews 199819 717-797.

38 Veldhuis JD, Bidlingmaier M, Anderson SM, Evans WS, Wu Z \& Strasburger CJ. Impact of experimental blockade of peripheral growth hormone $(\mathrm{GH})$ receptors on the kinetics of endogenous and exogenous GH removal in healthy women and men. Journal of Clinical Endocrinology and Metabolism 200287 5737-5745.

39 Hartman ML, Veldhuis JD, Johnson ML, Lee MM, Alberti KG, Samojlik E \& Thorner MO. Augmented growth hormone (GH) secretory burst frequency and amplitude mediate enhanced GH secretion during a two-day fast in normal men. Journal of Clinical Endocrinology and Metabolism 1992 74 757-765.

40 Wright NM, Northington FJ, Miller JD, Veldhuis JD \& Rogol AD. Elevated growth hormone secretory rate in premature infants: deconvolution analysis of pulsatile GH secretion in the neonate. Pediatric Research 199232 286-290.

41 Wu FC, Butler GE, Kelnar CJH, Huhtaniemi I \& Veldhuis JD. Patterns of pulsatile luteinizing hormone secretion from childhood to adulthood in the human male: a study using deconvolution analysis and an ultrasensitive immunofluorometric assay. Journal of Clinical Endocrinology and Metabolism $1996 \mathbf{8 1}$ 1798-1805.

42 van den Berghe G, de Zegher F, Veldhuis JD, Wouters P, Awouters M, Verbruggen W, Schetz M, Verwaest C, Lauwers P, Bouillon R \& Bowers CY. The somatotropic axis in critical illness: effects of continuous GHRH and GHRP-2 infusion. Journal of Clinical Endocrinology and Metabolism 199782 590-599.

43 Iranmanesh A, South S, Liem AY, Clemmons D, Thorner MO, Weltman A \& Veldhuis JD. Unequal impact of age, percentage body fat, and serum testosterone concentrations on the somatotropic, IGF-I, and IGF-binding protein responses to a three-day intravenous growth-hormone-releasing-hormone (GHRH) pulsatile infusion. European Journal of Endocrinology 1998139 59-71.

44 Roubenoff R, Rall LC, Veldhuis JD, Kehayias JJ, Rosen C, Nicolson M, Lundgren N \& Reichlin S. The relationship between growth 
hormone kinetics and sarcopenia in postmenopausal women: the role of fat mass and leptin. Journal of Clinical Endocrinology and Metabolism 199883 1502-1506.

45 van den Berghe G, de Zegher F, Baxter RC, Veldhuis JD, Wouters P, Schetz M, Verwaest C, Van der Vorst E, Lauwers P, Bouillon R \& Bowers CY. Neuroendocrinology of critical illness: effects of exogenous continuous thyrotropin-releasing hormone and its combination with growth hormone secretagogues. Journal of Clinical Endocrinology and Metabolism 199883 309-319.

46 Stoving RK, Veldhuis JD, Flyvbjerg A, Vinten J, Hangaard J, Koldkjaer OG, Kristiansen J \& Hagen C. Jointly amplified basal and pulsatile growth hormone secretion and increased process irregularity in women with anorexia nervosa: indirect evidence for disruption of feedback-regulation within the growth hormoneinsulin-like growth factor-I axis. Journal of Clinical Endocrinology and Metabolism $1999 \mathbf{8 4} 2056-2063$.

47 Fryburg DA, Weltman A, Jahn LA, Weltman JY, Samolijik E \& Veldhuis JD. Short-term modulation of the androgen milieu alters pulsatile but not exercise or GHRH-stimulated GH secretion in healthy men. Journal of Clinical Endocrinology and Metabolism 1997 82 3710-3719.

48 Bright G, Veldhuis JD, Iranmanesh A, Baumann G, Maheshwari H \& Lima J. Appraisal of growth hormone (GH) secretion: evaluation of a composite pharmacokinetic model that discriminates multiple components of GH input. Journal of Clinical Endocrinology and Metabolism 199984 3301-3308.

49 Shah N, Evans W \& Veldhuis JD. Actions of estrogen on the pulsatile, nyctohemeral, and entropic modes of growth hormone secretion. American Journal of Physiology $1999 \mathbf{2 7 6}$ R1351-R1358.

50 Shah N, Evans WS, Bowers CY \& Veldhuis JD. Oral estradiol administration modulates continuous intravenous growth hormone (GH)-releasing peptide-2 driven $\mathrm{GH}$ secretion in postmenopausal women. Journal of Clinical Endocrinology and Metabolism $2000852649-2659$.

51 Veldhuis JD, Roemmich JN \& Rogol AD. Gender and sexual maturation-dependent contrasts in the neuroregulation of growth hormone $(\mathrm{GH})$ secretion in prepubertal and late adolescent males and females. Journal of Clinical Endocrinology and Metabolism 2000 $852385-2394$.

52 Waters DL, Qualls CR, Dorin R, Veldhuis JD \& Baumgartner RN. Increased pulsatility, process irregularity, and nocturnal trough concentrations of growth hormone in amenorrheic compared to eumenorrheic athletes. Journal of Clinical Endocrinology and Metabolism 200086 1013-1019.

53 Van den Berg G, Frohlich M, Veldhuis J \& Roelfsema F. Growth hormone secretion in recently operated acromegalic patients. Journal of Clinical Endocrinology and Metabolism $1994 \quad \mathbf{7 9}$ 1706-1715.

54 Peacey SR, Toogood AA, Veldhuis JD, Thorner MO \& Shalet SM. The relationship between 24 hour growth hormone secretion and insulin-like growth factor I in patients with successfully treated acromegaly: impact of surgery or radiotherapy. Journal of Clinical Endocrinology and Metabolism 200086 259-266.

55 Schaefer F, Baumann G, Haffner D, Faunt LM, Johnson ML, Mercado M, Ritz E, Mehls O \& Veldhuis JD. Multifactorial control of the elimination kinetics of unbound (free) GH in the human: regulation by age, adiposity, renal function, and steady-state concentrations of GH in plasma. Journal of Clinical Endocrinology and Metabolism $1996 \mathbf{8 1} 22-31$.

56 Hansen TK, Gravholt CH, Orskov H, Rasmussen MH, Christiansen JS \& Jørgensen JO. Dose dependency of the pharmacokinetics and acute lipolytic actions of growth hormone. Journal of Clinical Endocrinology and Metabolism 200287 4691-4698.

57 Jansson J-O, Edén S \& Isaksson OG. Sexual dimorphism in the control of growth hormone secretion. Endocrine Reviews 19856 128-150.

58 Toogood A, Nass R, Pezzoli S, O'Neill P, Thorner MO \& Shalet SM. Preservation of growth hormone pulsatility despite pituitary pathology, surgery, and irradiation. Journal of Clinical Endocrinology and Metabolism 199782 2215-2221.

59 Roelfsema F, Biermasz N \& Veldhuis JD. Pulsatile, nyctohemeral and entropic characteristics of $\mathrm{GH}$ secretion in adult $\mathrm{GH}$-deficient patients: selectivity decreased pulsatile decrease and increased secretory disorderliness with preservation of diurnal timing and gender distinctions. Clinical Endocrinology 200256 79-87.

60 Jørgensen JO. Human growth hormone replacement therapy: pharmacological and clinical aspects. Endocrine Reviews 199112 189-207.

61 Pincus S, Veldhuis J \& Rogol A. Longitudinal changes in growth hormone secretory process irregularity assessed transpubertally in healthy boys. American Journal of Physiology $2000 \mathbf{2 7 9}$ E417-E424.

62 Shah N, Evans W, Bowers CY \& Veldhuis JD. Tripartite neuroendocrine activation of the human growth hormone $(\mathrm{GH})$ axis in women by continuous GH-releasing peptide infusion: pulsatile, entropic, and nyctohemeral mechanisms. Journal of Clinical Endocrinology and Metabolism $1999842140-2150$.

63 Evans W, Anderson S, Hull L, Azimi P, Bowers CY \& Veldhuis JD. Continuous 24-hour intravenous infusion of recombinant human growth hormone (GH)-releasing hormone-(1,44)-amide augments pulsatile, entyropic, and daily rhythmic GH secretion in postmenopausal women equally in the estrogen-withdrawn and estrogen-supplemented states. Journal of Clinical Endocrinology and Metabolism 200186 700-712.

Received 31 January 2006

Accepted 7 April 2006 